\title{
МИФ И КИНО: ОПЫТ РУССКОЯЗЫЧНОЙ ТЕОРЕТИЧЕСКОЙ РЕФЛЕКСИИ РУБЕЖА ХХ-ХХІ ВЕКОВ
}

\section{MYTH AND CINEMA: EXPERIENCE OF RUSSIAN-LANGUAGE THEORETICAL REFLECTION OF THE TURN OF THE XX-XXI CENTURIES}

\section{A. Dyatko}

Summary: The target of research is the myth as one of the components of cinema language and value orientations. The article is dedicated to the comprehension of the Russian experience of theoretical reflection of the last turn of the century about the mythological component of cinematography. The Operational Definition of myth and its functionality has been developed on the basis of the analysis of several options for the interpretation of myth in philosophical and cultural researches. A deeper understanding of the internal changes in the mechanisms of the myth when used in cinema is realized by addressing the legacy of the world cinema classics, such as J. Cocteau, A. Tarkovsky and others. Domestic researches on the use of myth in cinema of the 1990s and 2000s were chosen as an object for analysis because of the actualization of the myth in crisis times, as one of the ways to restore the lost ontological foundations of identity. The purpose of this article is to try to explain how native researchers consider mythological involvement in cinema, being in the conditions of forming a new model of social structure. Comparative and hermeneutic approaches have been used to achieve this purpose. They are taken as a foundation for distinguishing methodological variations of research approaches of the turn of the century. The relevance of this article is due, firstly, to the lack of generalization of theoretical reflection in recent years on the importance of the myth in cinema in Russia, and secondly, to the huge popularity of the myth currently among filmmakers, with the apparent ambiguity of its interpretations. The article postulates the reorientation of transitional era cinematography from screening myths and using them as an ideological tool to existential and ethnosocial problems in order to create an image of "universal reality". Conclusion: The need to further explore the theoretical legacy of the myth in cinema.

Keywords: transitional era, myth, Russian cinema, crisis, New wave, theoretical reflection, ethnomiphology, aestheticization, ideology, screening.

\author{
Дятко Алёна Игоревна \\ Аспирант, Московский государственный университет \\ имени М.В. Ломоносова \\ yapolka@mail.ru
}

Аннотация: Предмет настоящей статьи есть миф как один из компонентов киноязыка и взгляда на мир. Статья посвящена осмыслению отечественного опыта теоретической рефлексии рубежа XX-XXI веков по поводу мифологической составляющей кинотворчества. На основе анализа ряда вариантов истолкования мифа в философско-культурологических исследованиях, выведено рабочее понятие мифа и его функционал. Обращение к наследию классиков мирового кинематографа, таких, как Ж. Кокто, А. Тарковский и др., позволяет глубже понять внутренние изменения механизмов мифа при соединении его с кино. Отечественные исследования по использованию мифа в кино 1990-х и 2000-х гг. выбраны в качестве объекта для анализа по причине актуализации мифа в кризисное время, как одного из способов восстановления утраченных онтологических оснований идентичности. Задачей данной статьи является попытка объяснения, как в условиях формирования новой модели общественного устройства исследователи-соотечественники оценивают мифологическую включённость в кино. Для реализации означенной задачи были использованы компаративный и герменевтический подходы. Они берутся за основу при выделении методологических вариаций исследовательских подходов рубежа веков. Констатируется переориентация кинематографа переходных эпох от экранизации мифов и использования их как идеологического инструмента к экзистенциальной и этносоциальной проблематике в целях создания образа «универсальной реальности». Актуальность данной статьи обусловлена, во-первых, дефицитом обобщения теоретической рефлексии последних лет по поводу роли мифа в кино в России, и, в0-вторых, огромной популярностью мифа в настоящее время у киномастеров, при явной неоднозначности его интерпретаций. В статье сделан вывод о необходимости дальнейшего изучения теоретического наследия по проблеме мифа в кино.

Ключевые слова: переходная эпоха, миф, российский кинематограф, кризис, Новая волна, теоретическая рефлексия, этномифологизм, эстетизация, идеология, экранизация.

\section{Введение}

$\mathrm{M}$ иф и искусство во многом схожи. Так, «мифам свойственно претворение общих представлений в чувственно-конкретной форме, т. е. та самая образность, которая специфична для искусства и которую последнее в известной мере унаследовало от мифологии» [1, с.4]. Более того, миф входит в исследовательскую области целого корпуса гуманитарных дис- циплин: религиоведения, гносеологии, антропологии, культурологии, филологии, лингвистики, психологии, эстетики, а также идеологии и политических наук. Междисциплинарность явления, с одной стороны, повышает интерес со стороны исследователя, а с другой, размывает четкие рамки использования понятия.

Нынешняя эпоха предоставляет неограниченные возможности доступа к информации; создавая, од- 
нако, лишь иллюзорность обладания ею. Например, огромной пласт текстов последнего рубежа веков относительно соотношения мифа и кино до сих пор не систематизирован и пока еще не осмыслен в рамках единого исследования. В силу дефицита систематизации подобной теоретический рефлексии последних 20-30 лет в России, а также многозначности понятия «миф», его практической и теоретической актуальности в современном культуролого-эстетическом дискурсе, образовалась лакуна, требующая заполнения. Важно понять: как русскоязычные исследователи в условиях трансформации культурных детерминант оценивают мифологическую составляющую в кино? Привносит ли миф в него художественное и эстетическое наполнение, или же он является лишь опорной структурной матрицей донесения изолированного смысла художественного произведения?

\section{Миф}

Миф, мифология, мифологема, мифопоэтика, мифотворчество... Диапазон использования этих и производных от них понятий в современном общекультурном и философско-эстетическом дискурсах представляется пугающим даже для самого искушенного исследователя, не говоря уже о так называемом обывателе, - по причине своей плюральности и неопределённости внутренних коннотаций. Фактически «затёртые до дыр», с еле просматривающимися границами смыслов, «мифы» то и дело «снуют» в заголовках газет и журнальных статей, в критических отзывах и рецензиях на произведения искусства, в идеологически окрашенных, часто разоблачительных, слоганах. Несмотря на частую корреляцию знака «миф» «с взаимоисключающими значениями и употребляется не только как нечто многозначное, но и как весьма неопределённое» [2, с. 262], «мифы» всегда успешно выполняют функцию увлечения мысли реципиента за собой.

Сказанное в значительной мере объясняет выбор теоретиками одной из следующих методологий в трактовке мифа:

а) Преемственность» есть один из самых частых и простых путей, когда рабочая концепция мифа перенимается у одного из предшественников, чаще всего классиков данной проблемной области. К ним мы можем отнести О. Ранка, А. Ф. Лосева, Р. Барта, М. Элиаде.

б) Разработка собственного терминологического annapama.

в) Либо, что в последнее время встречается чаще всего, нежелание эксплицировать смысл рабочего понятия, даже если оно является важнейшим в данном труде. Такой подход мы назовём «инmуитивным» - когда автор, а с ним и читатель, блуждают почти наощупь в будто бы самих собой разумеющихся «мифах». Позиция эта в концентрированном виде представлена в докторской диссертации «Современность как история. Реализация мифа в документальном кино» современного искусствоведа Л. Мальковой. «Мы не стремились, - пишет она, - соблюдать терминологическую точность в нашей работе, полагая, что в контексте нам удастся прояснить, что мы имеем в виду» [3, с. 5].

Последний вариант обращения с заглавным термином, пожалуй, наиболее уязвим для критики. Почему? Бриколажно ассимилировавшись в прикладных сферах (будь то реклама или политтехнологии), в теоретической рефлексии миф часто оказывается «наедине с самим собой». В таком контексте правомерно говорить о метауровнях мифа, формирующихся в процессе его собственной мифологизации, да и культуры в целом [3, с. 12]. Такого рода постмодернистское осмысление феноменов зачастую ограничивает возможности более строгой научной разработки понятий.

Сформулируем рабочее понятие мифа путем обобщения суждений теоретиков, разрабатывавших данную область. И попутно постараемся уяснить, как соотносятся друг с другом теоретическая и практическая компоненты мифа.

Солидаризируемся с тезисом современного философа Д.П. Козолупенко: Миф есть формообразующее звено всей жизнедеятельности человечества, своеобразное «основание основания любой культуры» [2, с. 9].

Данное определение может идти вразрез как с популярной семиотической концепцией мифа, разработанной Р. Бартом, где миф предстаёт в идеологизированном фокусе как «особая вторичная семиологическая система» [5, с. 25]; которая в зародыше неверным, искажающим реально возможное восприятие предмета рефлексии. Мы не отрицаем правомерность такого подхода. Однако отождествление мифа с ложью может, в одном случае, вести к неоправданному упрощению того сложного теоретического и эстетического конструкта, который был разработан Р. Бартом. В другом случае актуализируется лишь второе значение словесного знака «миф» (в обывательском представлении). Главным представляется следующее: бартовский миф не отмершее порождение, но огромный пласт современной культуры, реализующий себя, в частности, в кино, рекламе и т. п. с помощью знаков и символов.

Переходим к следующим характеристикам мифа цикличности и его особой онтологической реальности. Вслед за классиком в области философии и, в частности, теории мифа и эстетики А.Ф. Лосевым, мы постулируем, что присущая современности реальность мифа [6, с. 50] 
обнаруживается при восприятии вещей вне естественной причинности, как чуда. Миф есть событие, в какомто смысле единожды произошедшее, но «повторяющееся постоянно» [7, с. 16]. Подтверждение этому тезису мы находим в работе Карен Армстронг, британского религиоведа и философа, «Краткая история мифа» (2005). Для современного человека, по Армстронг, эта цикличная мифореальность - кинематограф. «Добившись многого в материальной сфере, в сфере духовной мы не продвинулись дальше осевого периода; более того, отказавшись от мифа, мы, пожалуй, даже деградировали по сравнению с той эпохой.<...>Мы пытаемся «перейти порог»; «мы пытаемся забыться в волшебном мире кино» [7, с. 133].

Андрей Тарковский является одним из сильнейших мифотворцев от кинематографа, что видно во всех его произведениях. «Андрей Рублев», снятый в 1966 г. в СССР, переносит современного нам кинозрителя в средневековую Русь. Мифы берутся Тарковским не как нарратив, но лишь как архетипичные структуры, способные создать новую художественную реальность на экране. В частности, пристрастие Тарковского к использованию образа дождя как душеочистительного процесса базируется на древних мифологемах, связанных с потопами, присутствующими в том или ином виде во многих архаичных культурах.

Ситуация переноса прошлого в постоянно повторяющееся настоящее в полной мере обнаруживает себя в кинематографе: как за счёт «прямых метафор» (классический пример: библейское выражение «и камни возопиют» представлено в «Броненосце Потёмкине» С. Эйзенштейна встающими на дыбы каменными львами), так и ввиду «специфического синкретизма кинематографического языка» [8, с. 14]. В киноязыке цикличность не вступает в противоречие ни с глубинными архетипическими структурами нашей психики, ни с постоянным влечением человека к трансценденции.

К. Армстронг говорит о мифологии как об «особой форме искусства, устремленной за пределы истории ко вневременному ядру человеческого бытия» [7, с. 16]. Эта фраза представляется нам рельефным метафорическим описанием мифического, и одновременно она подтверждает мысль о сакральности, таинстве мифа, помогающего обществу переживать «переходные эпохи» истории или, в случае индивида, «пограничные состояния» (по К. Ясперсу). Мысль Армстронг созвучна интенциям и других теоретиков мифа, как «классиков» - Р. Барта, Ж. Делёза, М. Фуко, Е. М. Мелетинского, так и наших современников, создававших свои труды на рубеже веков (М. Альбедиль, В.А. Бачинина, Д.П. Козолупенко, Д. Маклюэна, Дж. Кэмпбелла, Н.Е. Почининой, Н.А. Хренова и многим других). Конечно, этот перечень не претендует на полноту, однако показывает, что в кон- це XX века присутствует тенденция понимать миф не как некий нарратив, присущий Древности и реальный только в ней, но как реальность современности, преобразованную в виде искусства.

Мифологического сознания в его чистом виде не существует со времен раздвоения европейского сознания на миф и логос. Отрыв мифа от своей практически ориентированной направленности исторически совпадает с зарождением древнегреческой философии. Что влечет за собой представление мифа лишь инструментом познания объективного и, как следствие, противопоставление его в этом отношении философии, в дальнейшем науке и религии.

Попытки отказываться от всего мифологического достигают апогея в период «проекта Просвещения», который не только не достиг своей рационалистической цели, но, напротив дискредитировал себя в XX веке огромным массивом иррационального в культуре, представленного исканиями в области искусства «потустороннего» и мифологического (если не мистического) (в начале - авангардизм, в конце XX века постмодернизм). В нашу эпоху ми ф наиболее сблизился с искусством, нашел в нём своё убежище, поскольку в переходные эпохи «искусство оказывается единственным средством институционализации личностного содержания» $[8$, с. 16]. В современных реалиях смещения акцентов культуры с литературоцентристских позиций на визуальные влечет за собой появление мифа в том модусе в кинематографе и медиаискусстве (которые в современной философии культуры именуют «виртуальными видами искусства»).

Веками не учитывавшаяся в теоретической литературе компенсаторика мифа, работающая в сфере искусства, начала активно разрабатываться в XX веке сначала психоанализом в индивидуализирующем подходе 3. Фрейда, а потом и в юнгианских понятиях архетипов, лежащих в основе коллективного бессознательного: «духовного наследия всего, что было пережито человечеством», «общей души, не имеющей временных пределов» [10]. Это - фундаментальная «предпосылка каждой индивидуальной психики, подобно тому как море есть предпосылка каждой отдельной волны» [10]. Идеи Фрейда и Юнга впоследствии лягут в основу воззрений М. Маклюэна, Д. Кэмпбелла и С. Жижека, которые, несмотря на все очевидные разночтения в понимании исследуемого предмета, связывают воедино визуальные искусства, психоанализ и активизировавшийся интерес к мифу.

Тенденшии понимания мифа в кино на рубеже XX-XXI веков

В философско-эстетических исследованиях, посвя- 
щенных использованию мифа в кино рубежа XX-XXI веков, мы выделяем несколько методологических вариаций.

1. «Мифопоэтика» в кино как способ восстановления утраченных онтологических оснований в кризисное время.

Эта линия активно развивается нашими соотечественниками, для которых актуальность утраченной идентичности очевидна в свете событий, развернувшихся в 1990-х гг. на территориях бывшего Советского Союза. Работающие в данном направлении авторы склонны рассматривать миф в кино с этномифологических позиций.

Например, Н.Е. Починина [см. 11] обращается к проблеме актуализации мифа в кино рубежа XX-XXI веков на базе творчества Э. Кустурицы. Основной тезис её исследования: «Диахронизм мифа тесно и органично перекликается с характерными принципами искусства XX-XXI века» [11, с. 5]. Что наводит на такие мысли: онтологичность мифа в современной информационной культуре отличается от классического мифа или архаической практики экзистенцией индивидуума, погруженного в современную среду потребительского общества. Индивид перестаёт быть субъектом мифа, включаясь в систему стихийного мифологизирования. С помощью мифа, как и с помощью искусства, можно эффективно влиять на структуры сознания, обращая реципиента к бессознательным архетипам, которые воздействуют сильнее, нежели попытки рационального объяснения реальности.

Почему при прочих равных условиях Почининой был выбран именно Эмир Кустурица, а не другой режиссёр, или вообще - режиссёры? Думается, потому, что его творчество - сугубо авторское, национальное и цельное. Основой стиля Кустурицы стали: темпераментная и жестко реалистичная интерпретация действительности; романтическая «анархия» образного ряда плюс лукавая мудрость «черного юмора» (близкая к латиноамериканскому так называемому «магическому реализму»). Еще одной особенностью его картин стало использование балканской экзотики и фольклора, особенно актуальное с началом распада Югославии. Он обращается к самобытному фольклору и архетипам его Родины. Снимая фильм про одну только страну, автор нашумевших «Времени цыган» и «Черной кошки, белого кота» заслужил международную славу не только «фестивального» режиссёра в рамках элитарной культуры, но и «народного» вообще. Этот факт говорит о том, что архетипические образы и мифологемы, которые использует автор, сильнейшим образом воздействуют на сознание кинозрителей.
Российский филолог и культуролог Н.Н. Гашева [см. 12]в своей статье «Современное российское кино: культурологический аспект» (2012) также поднимает вопрос этномифологизма авторского кинематографа в кризисных условиях страны, как попытки конкурировать с научным дискурсом в интерпретации смысложизненной проблематики. Через анализ семантико-стилевых решений в российском авторском кино «Новой волны» автор обнаруживает ««перекличку» художественных текстов отечественного кино» [12, с. 92]. Последняя, по её мнению, служит маркером «русской идеи», формируемой на основе православно-христианского архетипа, к которому всё больше обращаются режиссёры. В числе фильмов, которые анализирует автор, «Яр» М. Разбежкиной (2007), «Юрьев день» (2008) и «Изображая жертву» (2006) К. Серебренникова, «Овсянки» А. Федорченко (2010), «Кочегар» А. Балабанова (2010), «Кислород» И. Вырыпаева (2010), «Курьер» К. Шахназарова (1998), «Край» А. Учителя (2010), «Жила-была одна баба» С. Смирнова (2010). Этих авторов Гашева относит к так называемой «Новой волне» российского кино.

Анализ статьи Гашевой показывает, что, центральной для современного авторского кино является, как она полагает, проблема внутреннего раскола русского мира и утраты идеалов в свете событий 1990-х гг.. Режиссёры «Новой волны» рефлексируют над произошедшим в стране, прибегая не к монументальной форме эпосов, а к личной биографии героя, обычно «маленького человека», существующего по законам нелинейного времени, времени внутреннего, цикличного, экзистенциального и мифологического.

Автор комментируемой статьи излагает свои суждения по поводу всех вышеназванных фильмов. Однако их подробное изложение и «верифицирование» не входит в нашу задачу. Наша работа имеет целью подготовку подступов к теме эстетизации мифа в современном кинематографе.

В порядке исключения остановимся лишь на одном из затронутых Н. Гашевой примеров.

Главный герой фильма А. Балабанова «Кочегар» «маленький человек», представитель якутского этноса, который противостоит «большому», но безликому миру цивилизации. В сознании маленького героя прослеживается глубинное аксиологическое разделение на «свой - чужой», где первое - это добро, а второе - зло. Стало быть, бинарные оппозиции древних мифов живы; кочегар убежден, что плохие люди должны гореть, а хорошие - жить. Киноповествование находится как бы на границе между величественным античным эпосом и антиутопией. Сюжет фильма крайне минималистичен, как и его визуальный и аудиальный ряды. Последний представлен лишь гитарным фламенко Дидюли, погру- 
жающим зрителя в атмосферу пессимизма и цикличности, из которой невозможно выбраться. Сюжет концентрируется на краткой истории любви, предательстве и мести «маленького человека». Художественный мир фильма аллегоричен. По Балабанову, Россия 1990-х гг. жила видоизменными архаическими мифами. Отличие современных охотников от охотников эпохи палеолита в том, что ныне все табу сняты, а охота идёт на своих сородичей. В итоге мы имеем своего рода антиутопию, которая, однако, реально существовала в пространстве истории нашей страны.

\section{2. Миф в кино исследуется как идеологический ин-} струмент манипуляции сознанием.

Сначала Р. Барт с его «Мифологиями», а вслед за ним и М. Маклюэн [см. 4] с его коммунитативной концепцией медиа и СМИ, образуют собой фундамент идеологического понимания мифа и видеорядов. Маклюэн воспринимал технические экстериоризации человеческих способностей как мифометафоры: «Все средства коммуникации действующие метафоры» [4, с. 135] Как любая метафора, они переописывают мир. Язык медиа и кино - как и язык вербальный, жест, каденция и ритм. Все языки - технологии. Человеку не дано осознать воздействия средства, а потому он смотрит на мир через зеркало заднего вида: новые средства понимаются как продолжение старых, они видимы, но незамечаемы. Лишь художнику дано быть антенной нации. Быть художником значит управлять мифометафорами: «Художник из башни из слоновой кости переходит в башню управления обществом» [4, с. 135].

Представительницей аналогичной тенденции Л. Малькова [см. 3, 13]. В её диссертации присутствует развернутый анализ киноработ Дзиги Вертова, первого документалиста СССР: «Три песни о Ленине», «Кинооки» и «Киноправда». Автор обращается и к игровым фильмам, выбирая из них идеологическую составляющую; рассматриваются работы А. Довженко и С. Эйзенштейна. Bсех этих киномастеров исследовательница относит к мифотворцам. В центре внимания оказываются понятия «правды» и «образа правды». На заре советского кинематографа, в 1920-х гг., новому государству требовались поддержка и обоснование своей политической позиции со стороны кино. Малькова понимает «правду» в советском кино лишь с позиций инструментализма; сугубо идеологизированно. Однако мы осознаём, что в случае прочтения образа «правды» в чисто инструменталистском ключе, её идеологическое воздействие может быть расширено и на постсоветский российский кинематограф, что может вызвать достаточно «однобокое» прочтение.

3. Культуралистско-филологический подход: опыт экранизации мифов как литературного феномена с использованием особого художественного киноязыка.
Представление феномена мифа как нарратива одно из самых распространенных в социокультурном дискурсом. Мы это связываем, во-первых, с тем, что знакомство с мифами начинается у человека обычно с книги «Сказания и мифы Древней Греции». Во-вторых, современная постмодернистская философия тяготеет к пониманию всего мира как некоего текста, а это влечет за собой и определение мифа и кинематографа в русле нарратологии. Несмотря на то, что данная позиция спорная, следует рассмотреть и её.

Обратимся к недавно вышедшей статье М.А. Корецкой, посвященной экранизациям мифа в кино. Автор именует кинематограф «фабрикой мифов» [8, с. 13], поскольку есть «специфический синкретизм кинематографического языка» [8, с. 14]. Основной предмет рефлексии автора - это возможность перенесения образного языка мифа на язык кино. Такой перенос, по её мнению, принципиально возможен, так как изначально миф представлял собой «массу недискурсивных практик» [8, с. 14], в виде сакрального разыгрывания сакральных сюжетов. Что сообразуется с языком кино. Автор учитывает трактовку мифа как нарратива, что фактически не создаёт проблем для кино: ведь фильмы обычно строятся как раз по принципу повествования. Цикличность мифа, по мнению Корецкой реализуется в формате киносериалов, сиквелов и приквелов, фильмов с одним актером и т.д. Сакральное соединение в мифе реализма и чуда, в кино предстает слиянием спецэффектов и изображения обыденного, позволяя представить любой фантазм как «саму вещь» $[8$, с. 15].

В статье Корецкой присутствует важное разделение на макро- и микронаррации мифов, где в первую категорию входят эпосы, былины и предания, а во вторую отдельные мифы в узком смысле, а также легенды, былички и сказания. На примерах фильмов «Орфей» Жана Кокто (1949) и «Тени забытых предков» Сергея Параджанова (1964) автор показывает, что микронаррации могут быть успешно переведены на кинематографический язык в случае, если это кино авторское. Оно, в отличие от коммерческого, массового, может позволить себе быть метафорическим и этнографическим. Метафоричность мифа, представленная «лишь как пустая архетипическая структура» [8, с. 18], позволяет придать фильму большую художественную ценность и отдалиться от буквальности логики аутентичного мифа.

Р. Барт в своих «Мифологиях» приводит пример с «римлянами в кино» в ленте Манкевича «Юлий Цезарь», где все персонажи непременно должны носить чёлку, даже если она выглядит нелепо, - только потому, что она характеризует «римскость».

Для нас важно то, что М. Корецкая напрямую связывает природу мифа с метафорой, которая прибавляет 
художественную ценность кинокартине. Это внушает надежду на дальнейшее развитие эстетизации мифа в современном кинематографе.

\section{Зак^ючение}

Мы считаем необходимым изучение авторов, обращающихся к проблеме мифа в кинематографе, не как представителей некой единой школы, но как сторонников такой общей парадигмы, где каждый развивает ори- гинальные подходы к обоснованию своих концепций.

Неотъемлемыми характеристиками мифа, считаем мы, являются: цикличность, сакральность, ритуальность и обрядовость, его специфическая реальность и относительная нарративность, образность и символичность. Эта сложносоставность мифа, как и его языка, служит сопряжению мифа с кинематографом. Тем более - в переходную эпоху, когда актуализация мифа в искусстве явно нарастает.

\section{ЛИТЕРАТУРА}

1. Мелетинский Е.М. Поэтика мифа. СПб.: Азбука, Азбука-Аттикус, 2018. - 478 с.

2. Козолупенко Д.П. Мифопоэтическое восприятие. М.: «Канон+» РООИ «Реабилитация», 2009. - 432 с.

3. Малькова Л.Ю. Современность как история. Реализация мифа в документальном кино. М.: «Материк», 2001. - 188 с.

4. Маклюэн М. Телевидение. Робкий гигант // Современные проблемы личности : журнал / пер.: Григорьева Аркадьева. — М.: Издательтво «Икусство», 2001. — № 1. — С. 138-148.

5. Барт Р. Мифологии. М.: Изд-во им. Сабашниковых, 1996.

6. Лосев А.Ф. Диалектика мифа. [предисл. А.А. Тахо-Годи; примеч. В. П. Троицкого]. - М.: Академический Проект, 2008. - 303 с.

7. Армстронг К. Краткая история мифа. М.: Открытый мир, 2005. - 160 с.

8. Корецкая М.А. Экранизация мифа: трудности перевода / Вестник Самарской гуманитарной академии / Серия Философия. Филология, 2010, №1(7), С. 13-32.

9. Хренов Н.А. Искусство в исторической динамике культуры. М.: 000 «Изд-во «Согласие»», 2015. - 752с.

10. Огурцов А.П. Электронная библиотека. URL: https://iphlib.ru/greenstone3/library/collection/newphilenc/document/

11. Починина Н.Е. Мифопоэтика в современном кино: автореф. Дис. . . . канд. наук по специальности 24.00.01 - Теория и история культуры. - Томск:ТГУ, 2010. $-30 \mathrm{c}$.

12. Гашева Н.Н. Современное российское кино: культурологический контекст // Вестник КемГУКИ 21/2012. - С.90-100.

13. Хренов Н.А. Новая волна в российском кинематографе: фильмы А. Звягинцева // Теория искусства и художественное воображение XXI века. - 2011. №2(3). - - $.67-47$.

14. Малькова Л.Ю. Современность как история: Реализация мифа в отечественной кинодокументалистике. Диссертация на соискание ученой степени доктора искусствоведения: 17.00.03 Киноискусство, теле- и другие экранные искусства» Минкульт РФ, НИИ киноискусства. М., 2001. - 312 с.

15. Альбедиль М. Миф и реальность. СПб.: Вектор, 2014. - 256 с.

16. Кэмпбелл Дж. Тысячеликий герой. Спб.: Питер, 2016. - 352 с.

17. Леви-Брюль Л. Сверхъестественное в первобытном мышлении. М.: Педагогика-Пресс, 1999. - 607 с.

18. Леви-Строс К. Первобытное мышление. М.: Республика, 1994. - 384 с. 